\title{
Advances in Cancer Genomics
}

\section{Editor: Linda A. Cannizzaro}

In the past, there have been astonishing developments in the fields of molecular genetics and translational medicine. Investigations have shown that the cytogenetic and molecular genomic abnormalities in hematologic and solid tumor malignancies are specific to manifestation of disease development and progression. However, the heterogeneous nature of these genomic alterations has hindered understanding of their significance as the malignant state evolves and of their impact on survival and remission after treatment. The introduction of high-resolution technologies has helped to unravel the complexity of many cancer-associated genomic alterations. Studies like array comparative hybridization $(\mathrm{aCGH})$, single nucleotide polymorphism analyses (SNP), next-generation sequencing (NGS), and gene expression analyses (GEP), have facilitated a more thorough understanding of the pathology of hematologic and solid tumor neoplasms.

This issue contains representative articles to further knowledge of the manifestation and progression of cancer. It adds to the ongoing efforts to ultimately create personalized treatments and to eventually eliminate the devastation of malignancy in patients.

\section{Contents}

\section{Review Articles}

The Genomic Era of Clinical Oncology: Integrated Genomic Analysis for Precision Cancer Care: Surrey, L.F. et al.

Chromosome Imbalances in Cancer: Molecular Cytogenetics Meets Genomics: Palumbo, E.; Russo, A.

Human Papillomavirus and the Development of Different Cancers: Gao, G.; Smith, D.I.

Molecular Markers Involved in Tumorigenesis of Thyroid Carcinoma: Focus on Aggressive Histotypes: Penna, G.C. et al.

Fragile Genes That Are Frequently Altered in Cancer: Players Not Passengers: Karras, J.R. et al.

Role of the Common Fragile Sites in Cancers with a Human Papillomavirus Etiology:

Gao, G.; Smith, D.I.

Hypoxia Pathway Mutations in Pheochromocytomas and Paragangliomas:

Amorim-Pires, D. et al.

\section{Original Articles}

The Genomic Landscape of PAX5, IKZF1, and CDKN2A/B Alterations in B-Cell Precursor Acute Lymphoblastic Leukemia: Ou, Z. et al.
Genomic Characterization of a Metastatic Alveolar Rhabdomyosarcoma Case Using FISH Studies and CGH+SNP Microarray Revealing FOXO1-PAX7 Rearrangement with MYCN and MDM2 Amplification and RB1 Region Loss: Karunamurthy, A. et al.

The Dicentric Chromosome dic $(20 ; 22)$ Is a Recurrent Abnormality in Myelodysplastic Syndromes and Is a Product of Telomere Fusion: MacKinnon, R.N. et al.

Isodicentric Philadelphia Chromosome: A Rare Chromosomal Aberration in Imatinib-Resistant Chronic Myelogenous Leukemia Patients - Case Report with Review of the Literature: Ramachandran, K.C. et al.

\section{Short Report}

Identification of a Cryptic Insertion ins $(11 ; \mathrm{X})$ (q23;q28q12) Resulting in a KMT2A - FLNA Fusion in a 13-Month-Old Child with Acute Myelomonocytic Leukemia: Lentes, J. et al.

\section{Case Report}

Coexpression of NUP98/TOP1 and TOP1/ NUP98 in de novo Acute Myeloid Leukemia with $t(11 ; 20)(p 15 ; q 12)$ and $t(2 ; 5)(q 33 ; q 31)$ : Yamamoto, K. et al.

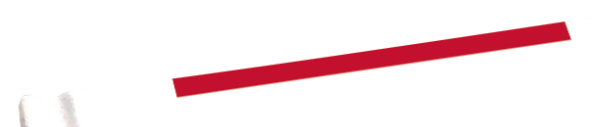

Advance
Cancer Linda A.Cannizz

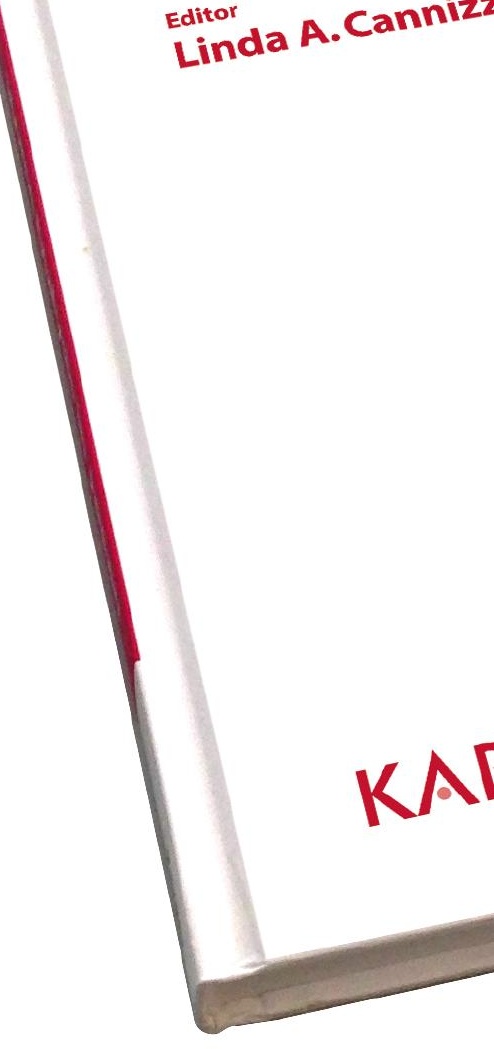




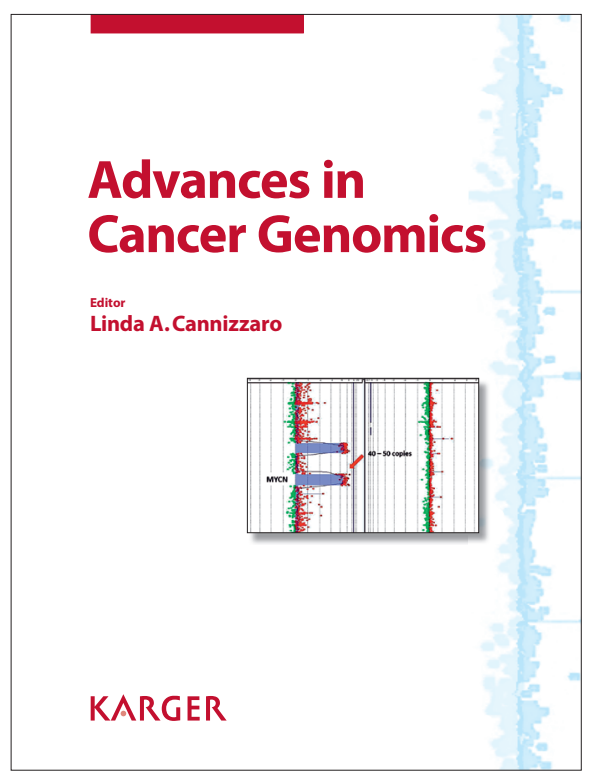

Journal reprint of Cytogenetic and Genome Research Vol. 150, No. 3-4 (2016)

\section{Advances in Cancer Genomics}

Editor: Cannizzaro L.A. (New York, NY)

138 p., 30 fig., 10 tab., 2017

CHF 96.00 / EUR 90.00 / USD 113.00

(hard cover or online*)

CHF 115.00 / EUR 108.00 / USD 136.00 (online**)

ISBN 978-3-318-06045-4

e-ISBN 978-3-318-06046-1

www.karger.com/cgr

\section{FIELDS OF INTEREST}

Genetics; Oncology; Genomics, Hematology, Leukemia, Molecular Biology

\section{Further publications in the field}

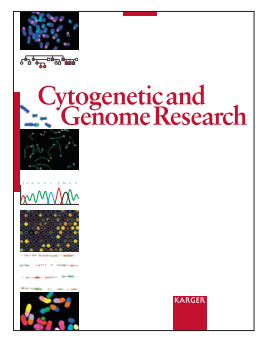

Of related interest
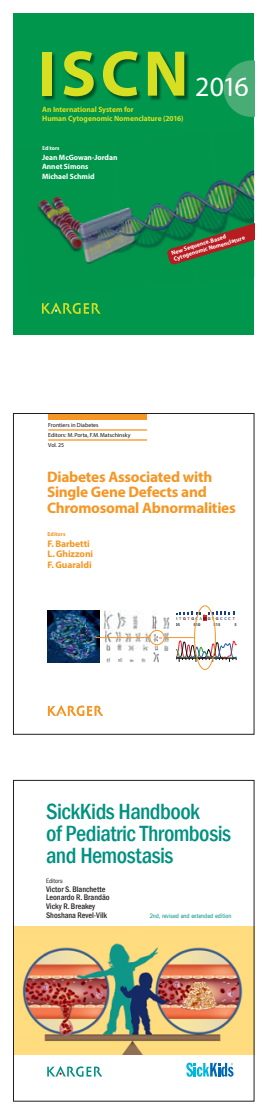

Cytogenetic and Genome Research

Editor-in-Chief: M. Schmid (Würzburg)

Listed in bibliographic services, including:

PubMed/MEDLINE, Web of Science, Google Scholar,

Scopus, Embase

2017: Volumes 151, 152, 153 / 4 issues per volume

Language: English

ISSN 1424-8581 / e-ISSN 1424-859X

Current Impact Factor: 1.638

www.karger.com/cgr

\section{ISCN 2016}

Reprint of Cytogenetic and Genome Research, Vol. 149, No. 1-2, 2016 ISCN 2016

An International System for Human Cytogenomic Nomenclature (2016)

Editors: McGowan-Jordan, J. (Ottawa, Ont.); Simons, A. (Nijmegen); Schmid, M. (Würzburg) VI + 140 p., 10 fig., 4 tab., + foldout, 2016 CHF 49.00 / EUR 46.00 / USD 51.00 (soft cover)

ISBN 978-3-318-05857-4

www.karger.com/ISCN2016

Frontiers in Diabetes, Vol. 25

Diabetes Associated with Single Gene Defects and Chromosomal Abnormalities

Editors: Barbetti, F. (Rome); Ghizzoni, L.; Guaraldi, F. (Turin) $X+192$ p., 20 fig., 11 in color, 10 tab., 2017

CHF 178.00 / EUR 166.00 / USD 209.00

(hard cover or online*)

CHF 214.00 / EUR 199.00 / USD 251.00 (online ${ }^{* *}$ )

ISBN 978-3-318-06024-9 / e-ISBN 978-3-318-06025-6

www.karger.com/fid

\section{SickKids Handbook of Pediatric Thrombosis} and Hemostasis

Editors: Blanchette, V.S. (Toronto, Ont.); Brandão, L.R. (Toronto, Ont.); Breakey, V.R. (Hamilton, Ont.);

Revel-Vilk, S. (Jerusalem)

$X X+338$ p., 31 fig., 13 in color, 10 algorithms, 80 tab., hard cover, 2017

CHF 127.00 / EUR 119.00 / USD 149.00 (hard cover or online*) CHF 152.00 / EUR 143.00 / USD 179.00 (online ${ }^{* *}$ )

ISBN 978-3-318-03026-6 / e-ISBN 978-3-318-03027-3 www.karger.com/SickKids
Library Recommendation

Dear Librarian

I have reviewed Advances in Cancer Genomics and would like to recommend it for your library

Recommended by:

Department:

Date:

Signature:

ebooks are available on

amazon Google play Vitalsource 